\title{
Difficulties and Ideas in Standardized Management of Sluice
}

\author{
Yao Fengchun \\ Water Supply Bureau of Shandong Yellow River Bureau, Jinan, China
}

\section{Email address:}

122703986@qq.com

\section{To cite this article:}

Yao Fengchun. Difficulties and Ideas in Standardized Management of Sluice. Science Innovation. Vol. 9, No. 4, 2021, pp. 173-175. doi: 10.11648/j.si.20210904.21

Received: May 20, 2021; Accepted: July 6, 2021; Published: July 9, 2021

\begin{abstract}
At present, the scale of sluice construction in China is becoming larger and larger. How to solve the difficulties in engineering construction and improve the quality of sluice project is the key to ensure the development of water conservancy projects during the "fourteenth five year plan". In water conservancy projects, sluice is the key hydraulic structure for flood control, storage and drainage. It is mainly constructed through the sluice gate to retain water, the drip head in the discharge and the hydraulic structure, so as to play the role of water storage, interception, control, tide retaining and interception, so as to ensure the smooth development of upstream water diversion operation and ensure the actual demand of navigation. When the sluice gate is opened, it can achieve the purpose of drainage, scouring and silting, and water diversion. At the same time, it can dynamically adjust the flow according to the downstream water demand. At present, sluices are widely used in coastal areas, reservoirs, lakes, canals, rivers and other areas in China. Its quality directly affects the safety of people's lives and property. However, the construction quality problems often occur in the sluice construction because of its complicated process and complex construction environment. Therefore, in order to ensure the application effect of the sluice and the application effect of the sluice, this paper puts forward the control ideas for the difficulties in the construction process of the sluice, in order to achieve the effect of standardized management.
\end{abstract}

Keywords: Smart Water System, Urban Water Supply, Application, Research

\section{水闸规范化管理中的难点与思路}

\section{姚逢春}

山东黄河河务局供水局, 济南市, 中国

邮箱

122703986@qq.com

摘要：目前，我国水闸建设规模越来越大，如何解决工程建设中的难点，提高水闸工程质量，是保证“十四五”期间水 利工程水利发展的关键。在水利工程中, 水闸是防洪、拦蓄、排涝的关键水工建筑, 主要是通过闸门挡水以及泄水中 的滴水头以及水工建筑物进行施工, 以起到蓄水、拦截、控制、挡潮和拦截的作用, 从而确保上游引水作业顺利开展, 保证通航的实际需求。水闸闸门开启的时候，能够达到排涝、冲淤和引水的目的，同时，可根据下游的需水量对流量 进行动态调节。目前, 水闸在我国滨海城区、水库以及湖泊、渠系、河道等地区被广泛的应用, 它的质量直接影响到 人民的生命和财产安全。但是水闸的施工因其工序繁琐、施工环境复杂等因素造成经常出现施工质量问题。因此, 为 了确保水闸应用效果以及水闸应用效果, 针对水闸施工过程中的难点提出控制思路, 以求达到规范化管理的效果。

关键词：水闸，规范化管理，难点，思路 


\section{1. 引言}

目前, 我国马上进入第十四个五年计划, 经济、社会 快速发展。在水利工程中, 水闸是防洪、拦蓄、排涝的关 键水工建筑, 主要是应用闸门挡水以及泄水中的滴水头以 及水工建筑物进行施工, 来控制、拦截和挡潮以及蓄水, 以确保上游取水作业顺利开展, 保证满足通航的实际需求。 水闸闸门开启的时候, 能够实现泄洪以及排涝与冲沙与取 水目的, 也能够结合下游的用水需求调节水的流量 [1]。目 前, 水闸在我国滨海区域、水库以及胡泊、渠系、河道等 地区被广泛的应用, 它的质量直接影响到人民的生命和财 产安全。但是水闸的施工因其工序繁琐、施工环境复杂等 因素造成经常出现施工质量问题[2]。因此, 为了确保水闸 应用效果以及水闸应用效果, 针对水闸施工过程中的难点 提出控制思路, 确保管理规范化与效果。

\section{2.水闸规范化管理中的难点与重点[3]}

\section{1. 开挖施工管理难点与重点}

因为工程建设较为复杂, 增加开挖施工难度, 再受 到一些施工人员缺失经验等影响, 导致开挖施工期间出 现开挖深度不够以及效果差等问题。针对此类问题, 要 通过制定合理开挖施工方案, 明确开挖施工重点和难点, 做好测量放线以及角度和深度等具体参数设计工作, 利 于良好控制和高效落实开挖施工作业[4]。在开挖施工 过程中, 技术员必须严格按照施工方案进行施工, 找到 腰线的精确位置, 以确保开挖的基坑符合设计要求。

\section{2. 金属结构质量控制难点与重点[5]}

金属结构工程是水利工程建设的重点, 因此, 施工期 间, 要依据相关要求和规范进行施工, 结合不同种类的水 闸项目以及金属结构, 选择适合的设计方法。目前, 市场 中金属材料的种类较多, 因此, 在实际施工环节, 施工人 员可以结合具体情况与实际需求, 选择适合的材料种类, 并进一步依据施工条件和要求, 进行科学的运输, 以此确 保金属材料安全运输, 确保材料的质量和完整性[6]。

\section{3. 日常养护难点与重点}

水闸工程日常维护的重点包括机电设备的维护、电气 设备。线路和启闭机、吊头、闸门等设计工作。因为水闸 常被修建在河流以及胡泊周围, 因此, 在常被气候等因素 影响, 导致设备出现不同程度破损问题。针对于此, 必须 重视水闸日常维护工作, 依据《水闸技术管理标准》等要 求, 建立一定周期, 有序进行维护和管理, 遏制各类安全 隐患的发生, 确保水闸可以正常的运行。

\section{4. 集中管理难点和重点}

因为水闸所处的河段区域位置不同、且较为分散, 这 样将增加管理的难度。一方面来说，水闸所处位置不同以 及分布较为零散, 将无法落实集中化管理, 降低了管理的 效率。此外，闸站的分布过于分散，也将导致增加实水利
闸站的工作量以及压力。针对于此, 在水闸管理期间, 应 建设完善的管理体系, 强化管理效率, 解决目前管理难度 较大问题。

\section{3. 水闸规范化管理的思路分析}

\section{1. 前期管理工作}

施工前期的管理工作是确保施工顺利开展的途径, 也 是实现高质量施工的保证与基础前提[7]。因此, 施工单位 需要在施工之前, 优先做好施工的管理工作, 重点对施工 方案实施审核, 也要保证施工队伍具备高水平的施工能力、 专业素养以及职业素养, 施工之前优先对施工图纸全面审 核, 详细和细致化的对施工图纸进行研究, 掌握施工图纸 的技术方面指标与相关的注意事项。与此同时, 也要结合 以往工程施工经验, 预防常出现的各类问题 [8]。

要注意的是, 在施工期间, 施工人员也要清楚的意识 到, 对于施工管理工作来说不仅仅单一是一个管理体系, 其也涉及到不同方面内容。因此, 在施工之前, 施工单位 还需建设专门性水闸施工管理组织以及小组, 依据工程建 设实际情况, 制定科学以及合理、规范化的施工管理制度, 来对施工进行有效的管控与监督工作, 以此强化施工质量, 避免出现各类施工问题[9]。

\section{2. 过程管理工作}

过程管理工作中, 要重点对以下几个方面工作进行管 理:

首先, 要做好开挖阶段的施工管理工作。水闸工程作 为一项系统化和大规模工程, 其作为水利工程建设重要构 成部分, 具备自身的特点, 如施工单位较为宽泛, 施工难 度较大等[10]。针对于此, 必须重视对水闸工程施工过程 管理工作, 强化整个施工过程的质量。

开挖施工时过程施工中关键和要点, 开挖工程的质量 对水闸工程建设整体质量影响较大, 因此, 要作为重点。 避免出现开挖断面过大以及过小问题, 因为, 若是开挖的 断面过大则将增加工程量, 若是断面过小, 则会对水闸的 强度带来影响 [11]。所以, 施工人员要重点对开挖施工进 行管控, 保证开挖工程和设计要求相吻合, 并在施工完毕 后及时开展工程验收工作 [12]。

此外, 也要做好混凝土施工质量管控工作, 重点对原 材料以及混凝土材料质量的控制进行管控 [13]。因为, 混 凝土原材料的管控影响施工质量, 所以必须重点对钢筋以 及水泥等原材料实施管控, 严格按照方案要求进行混凝土 材料配比, 控制好混凝土搅拌的用水量和骨料, 注意在混 凝土搅拌过程中的温度。安排专门人员, 不定期对原材料 实施检测, 并进一步提升质量管控工作人员的工作能力以 及素养, 以此确保质量检测结果的精准性与有效性。

\section{3. 后期管理工作}

后期管理工作中，针对施工管理单位以及监理单位 来说, 其要安排专业化质量检测工作人员, 建设质量检 测工作小组来对整个工程建设质量实施检查, 并在检查 期间重点对关键工序以及容易出现问题的各个部位实施 
检测, 利于及时发现问题, 及时管控和处理。待检测完 毕以后, 要交给项目法人由于其安排专门人员, 来对整 个工程建设质量进行检查与核定, 并再次对工程建设中 产生各类数据和信息进行划分和归档与财产, 然后才可 以交付并使用。

\section{4. 水闸管理期间需要注意的问题}

(1)实际管理环节, 要尊重生态环境的建设, 把保护河 流作为前提，树立为人民服务的管理理念，积极的把人民 群众的生活需求融入到城市化建设中 [14]。

(2)大力引进和应用科学技术, 对水闸实施监控和和管 理, 及时获管理以及维护信息, 及时做好记录, 利于对水 闸进行自动化以及智能的管理。

(3)做好运营成本的管控工作, 结合城市的生态化建设 进度与发展实际情况, 优化工程安全与运行安全二者之间 的关系, 做好汛期洪水的质量和用水之间矛盾的解决工作, 把水闸工程建设的经济效益放在首位。

(4)大力进行宣传和开展宣传活动, 积极引导公民参与 到河流保护等工作中, 维护生态区环境, 营造良好生态自 然环境好, 建设科学与合理化管理机制, 利于实现现代化 管理目标, 构建生态文明型城市。

\section{4. 结论}

综上所述, 我们可以看出, 城市水闸管理期间, 要 依据如下思路和流程进行管理首先要完善对水闸管理制 度和相关体系, 把安全管理作为管理的基础, 结合水闸 工程的具体情况, 及时检测和改进。然后, 要对环境卫 生以及绿化带的管理, 把城市区域内的卫生打扫工作具 体划分, 并落实到每个人身上, 要求每个人做好自身分 内的工作。并在绿化带的管理中, 重点对施工期间原材 料的控制以及混凝土的配置进行管理, 以免混凝土浇筑 出现裂缝以及蜂窝以及裂缝等问题 [15]。在具体管理期间, 应优化强化治安的防范与管理, 对不文明与危险行为进 行管控, 坚持以为人民服务作为管理理念, 积极把人民 群众的生活需要融合到城市建设中, 利于建设现代化、 生态化文明城市。

\section{参考文献}

[1] 杨爱山, 傅建. 浅析水闸现代化运行管理 [J]. 治 淮,2020,(10):44-46.

[2] 程燕. 水闸施工技术在水利工程中应用 [J]. 建筑遗 产,2013,(19):304-304.

[3] 申婉.探讨水闸规范化管理中的难点与思路 [J].建筑与装 饰,2020,(14):88-89.

[4] 易景文.中小型水闸维修养护关键技术及规范化管理分析 [J].科技经济导刊,2020,28(21):47-48.

[5] 邹志忠. 浅谈大跨度钢结构施工质量控制中重点、难点以及 重难点的解决[J].中国包装科技博览,2010,(19):129-130.

[6] 孔令清.水闸规范化管理中的难点与思路 [J].江淮水利科 技,2020,(01):12-13.

[7] 熊有松.总承包管理模式下的质量管理 [J]. 建筑模 拟,2019,(02):13-14.

[8] 刘同旭.平原地区病险水闸危害现状及规范化管理对策探 析[J]. 地下水,2019,44(04):221-222.

[9] 徐荣光.建筑工程质量监督工作中存在的问题与建议 [J].建 筑细部,2019,(05):23-23.

[10] 钟胜文.工程施工企业信息化管理应用 [J].科学与财 富,2017,(24):26-27.

[11] 王海方.浅谈水利水电工程中的水闸施工技术 [J].建筑细 部,2018,(16):39-40.

[12] 高玉琴,陈鸿玉, 肖璇,徐津.基于云理论的大中型水闸工程管 理现代化评价 [J].水利经济,2020,35(02):63-68+78.

[13] 张学龙.浅谈商品混凝土质量现状及管控措施 [J]. 商品混凝 土,2018,(12):17-19.

[14] 商涛,姜延强,罗建刚.芦家河管理处加强水闸规范化管理的 措施[J].山东水利,2021,(09):61-62.

[15] 李军凤.市政道路绿化带施工和质量控制 [J]. 建筑细 部,2010,(08):75-75. 